\title{
Use Of Language In Science Education - A Case \\ Study Of Malayalam *
}

\section{Saratchandran Nair}

\begin{abstract}
Language use in education has been an issue in a multilingual set up dominated by a colonial language, such as English which has become an over pervading effect because of its global stature vis-à-vis regional language/vernacular. Science education at the school level and at the higher education are not in contiguous relationship that the students switching over from the secondary level to higher secondary level faces umpteen issues that there are many drop outs and become recluse to their studies or have to deviate from their chosen path and one of the impediments is language issues, particularly switching from regional language medium to English language medium. The paper examines such issues based on an empirical study conducted by the author and the results are discussed.

Use of language in Science and Technological Studies has posed serious problems with regard to imparting knowledge, particularly the use of vernacular/regional Languages as opposed to the use of English in Science or technical education. It has been very often seen that the greatest impediment of regional languages is in the case of Science education that the students prefer to use English in Science education rather than the regional language. A student who had studied up to high school in Malayalam medium finds it very difficult to cope up with the Science education at intermediate/plus two stage and further on, compared to an English medium student. Owing to this many students drop out of education or become recluse with their studies. The question posed in this paper is that have these issues been addressed properly by administrators, planners, educationists, linguists, etc. It is also observed that the scientific terms used in the lower classes are not standardized, the concepts are not made clear and science education in regional languages takes
\end{abstract}


a back seat and the use of English is predominant and preferred. In order to investigate this problem an empirical study was undertaken in Kerala, particularly eliciting information from students, teachers, and educationists. The results of which are reported.

1. Science and Technological advancement of any country is an indicator of its socio - economic advancement. To an extent we could say that the socioeconomic control rests on this edifice and language plays a vital role in imparting knowledge. In the world of knowledge societies, information is power and power determines every walks of life. Currently, India is in the threshold of this situation. In this context, we should ask the question as to the role played by the Indian languages as opposed to the hegemony of English. Mahatma Gandhi was prepared to accept chaos in education and thinking in the complete switch over from English to the Indian languages as he believed that it would ultimately lead to creativity and originality in thought. It is true that acceptance of English was an historical coincidence; we have come to a stage that we can neither forsake it nor accept it completely at the cost of our Indian languages. The reality is that it is making inroads in to the daily polity that our children are bereft of thinking in the vernacular languages/regional languages and there seems to be erosion in the regional languages leading to cultural erosion. The present paper shall examine the issue of education of science in regional language, taking a case study of Malayalam, a language of the Dravidian family.

\section{Scope of the Paper}

It is seen that science education in Malayalam commences from early stage of class I and continues up to the stage of class X. In class I itself the concepts of environment, hygiene, better living are indoctrinated mostly through oral medium and the teaching of the written text commences from class IV and serious attention is given to science from Class IV onwards up to class X. At the stage of higher secondary level, there is a sudden switch over from Malayalam 
medium to English medium in Science education. Even though theoretically students can appear for subjects like Physics, Chemistry, Mathematics, zoology and Botany in Malayalam medium, there is no student, who opts to .write in Malayalam. There is no college which offers to teach the above subjects in Malayalam. In order to cope up with the difficulties the students face from Malayalam medium to English medium at the plus two level, now there are guide books which translates verbatim the English text books. It is in fact like teaching English literature through Malayalam or teaching English literature through Kannada. This fallacy occurs owing to our ill planning of science education in regional languages. There seems to be a large number of drop outs at this stage that English language becomes a hindrance to the career of many an youngster, who, otherwise would have been highly potential.

\section{Sample}

In order to examine this issue a sample survey was conducted among 30, plus two students at Trivandrum. All of them studied up to Xth Std. in Malayalam medium. The present study was only a pilot study and did not examine several variables. However factors such as rural vs urban and income of the parents were taken in to consideration as variables. The urban students constituted $66.66 \%$ and rural group was 33.33. income was grouped as above Rs.5000 as high, Rs.1000- as middle and below Rs. 1000/- as low income group.

\section{Analysis}

To a question as to whether they have faced difficulty while learning Science through Malayalam, 50\% answered affirmatively and $50 \%$ negatively. Those who have answered affirmatively had reasons to state such as when they were studying science at the school level many words were in English only and to understand the meaning of such words were difficult. Some words were translated in to Malayalam however many words were transliterated in Malayalam script. On examining the IXth Std, Physics text book it is seen that many words are written in Malayalam and the English renderings 
are provided in brackets. For example /aakkam/ (Momentum), / pRaveegam/ (velocity). /piNDam/ 'Mass" etc. If one examines the chemistry text book of Std IX, it is seen that many scientific words of chemistry are not translated in to Malayalam but are transliterated in to Malayalam. In Physics text book (ibid;7) mass is translated as /piNDam/ where as in Chemistry text book the English word is written in Malayalam script (13). There seems to be incompatibility across the disciplines for the same standard/class with regard to use of technical words in Malayalam and no strict guidelines are followed.

To a direct question as to whether the students faced difficulty while switching over from Malayalam to English medium at plus two level, $86 \%$ felt they found it difficult and the only fact is that the degree varied. Some have expressed, for many months, they did not understand anything what was taught and have stated that there were lot of spelling mistakes. One student has stated that he could not understand the meaning of English words and some words such as / saantrata/ 'density', /aaveegaM/' 'impulse' have created confusion. At the school level he has studied /pRaveegam/ as velocity/tvaraNam/ as acceleration. He has stated that clear cut distinction was not made at the school level and has created confusion. Similarily in Chemistry the words like 'catalyst' /utpreerakaM/ etc.. and in Physics 'inertia' / jaDatvaM/have compounded his confusion.

Regarding the choice of Medium of education at the plus two level a question was sought, as to whether they prefer English or Malayalam.

\section{Preference for medium of Instruction at plus two level}

\begin{tabular}{|c|c|c|}
\hline English & Malayalam & Not stated \\
\hline $80 \%$ & $16.6 \%$ & $3.3 \%$ \\
\hline
\end{tabular}


The reasons for choosing English were given as (i) language of wider communication (ii) could acquire greater knowledge (iii) knowing better English is essential (iv) further examinations are conducted in English (v) for continuing higher education and easy for higher education. The students 2 hailing from lower income prefers learning in Malayalam is easy and (ii) considers Malayalam is the mother tongue, so there is a need for providing materials in Malayalam .

\section{Discussion}

From the above analysis it is seen that there is no clear cut language policy while switching over from Malayalam medium to English medium at the plus two level catering to the needs of the students. It should have been a smooth switch over from Malayalam to English without being detrimental to their career. Plus two stage is a level at which too much of material is crammed together and there is substantial difference between the inputs at secondary level and higher secondary level. There seems to be no one to one correspondence between terms used in Physics and Chemistry text books and once again the language policy adopted by the education department of Kerala Govt. is questionable. In Physics text books in Malayalam English translations are provided in brackets, where as in Chemistry textbooks, the transliteration of English words in Malayalam is provided. It is seen that Malayalam language occupies a subordinate position and the hegemony of English is predominant.

In order to foster the development of Malayalam language in science education there were efforts made by Scholars and politicians in the sixties and seventies. The scholars such as Sri P.T. Bhaskara Panicker, Prof. N.Y. Krishna Variar, Shri Achyuta Menon, the former Chief Minister of Kerala and Shri E.M. Sankaranan Nambudiripad, the veteran communist leader and the former Chief Minister were in the fore front and the book by Sri. E.M.S. 'nammute bhaasha' is worth remembering. Prof. Krishna Variar took efforts in the establishment of the State Institute of Languages (bhaasha institute), the primary 
objective of which was to impart science education in Malayalam at the higher secondary and graduate level. Journals or magazines dealing with science or scientific literature were developed. The children's magazine 'uRika' and the journal published by State Institute of Languages, 'vijnaanakairali' are popular. Establishment of 'SaastRa saahitya parish at, an organization for literary movement in science has done yeoman service in spreading science through Malayalam. It has developed radical thinking and has created scientific awareness. All these efforts have not created an atmosphere conducive to science education in Malayalam, which was one of the desired goals. Teaching science in Malayalam at higher levels was envisaged, but was never done to its fullest extent.

However social science subjects are taught at higher levels in $\mathrm{Mal}$ ay al am. If one sees the development of science and Technology, be it in the field of bio-technology, information technology or space science it has immense potential of growth and developed nations have acquired knowledge and have used the benefits of science and technology to manipulate and exploit the development of third world countries. In this context Chomsky (1973 b: 77) states that "it seems reasonable to expect that control over Science and Technology will be essential for ruling groups in the advanced societies both for internal repression and imperial domination". The language of wider communication, English, plays a decisive role undermining the interests of vernacular languages and cultures.

\section{Note}

1. Among 30 students, only 16 students have stated their parent's mcome, so this variable could not be further explored. In an earlier study of the Migrant Malayalees in Mysore (Nair, V. Saratchandran, 1993) it was seen that the higher income group shows a preference for education in English than for their mother tongue. Lower income group prefers to study in mother tongue. In this study also it is seen that lower income groups prefers to study in Malayalam. 


\section{REFERENCES}

bhautika saastRam, 1999. Text books for IX Std. Education Dept. Kerala Govt.

Chomsky, Noam, 1973 a., For Reasons of State, New York, Pantheon Books

Nair, V Saratchandran, 1993. Migrant Malayalees in Mysore A case study of Language related issues PJDS, I vol. 3.1.(1-15)

resatantRam, 1988. Text book of IX Std. Education Dept. Kerala Govt.

Sankaran namputiripad, E.M. 1997. nammuTe bhaasha (Malayalam)

* Revised paper which was presented at the Seminar on Language Education in India, 7th Jan. 2002 to 9th Jan 2002, CAS in Linguistics, Annamalai University, Annamalainagar 